\title{
Research on Structural behavior of Composite Materials on different Cantilever Structures using FSI
}

\author{
Naveen Kumar K, Vijayanandh R, Bruce Ralphin Rose J, Swathi V, Narmatha R ,Venkatesan. K
}

\begin{abstract}
The implementation of composite materials in industries like aerospace, automotive, civil, naval, etc., are emerging continuously because of its combined unique effects. The present article deals with a numerical simulation of the natural frequency effect on the different cantilever structure for various composite materials also estimates its structural response to aerodynamic forces using Fluid-Solid Interaction (FSI) in Ansys Workbench environment. This work is intended to analyze and learn the response of various real-time structural parameters like maximum deformation, maximum stress-induced location and modal parameters like modal frequency, mode shapes on different Cantilevered structures. Structures like wind turbines, airplane wings are critical in structural behavior, which are characteristically using the wind to produce power and lift respectively. The present article deals with an estimation of natural frequencies for the prediction of working lifespan and structural parameters variation throughout the cantilever structures to multi-purpose usage. The entire comparative part of this article is executed with an acceptable simulation of the displacement and principal stress for different composite materials such as Kevlar, Glass Fiber Reinforced Plastic (GFRP) and Carbon Fiber Reinforced Plastic (CFRP) by using FSI. Composites Beams are modeled in CATIA and discretized in the Ansys ACP 16.2 tool and Modal analysis of various crosssectional beams are reported, compared and discussed.
\end{abstract}

Keywords: Composite; Lifetime; Fluid solid interaction; Oneway coupling; Optimization;.

\section{MATERIAL OPTIMIZATION}

Numerical simulations and its optimizations are considerable outcome in the design and material of the cantilever structure. In this paper the material optimization of cantilever structure takes place, in which the optimization is to find the ideal structure with high load withstanding capability followed by low weight [1]. The estimation parameter of the optimization depends on strain energy induced on the laminated composite material cantilever structure. Generally composite materials are advanced but in this case most appropriate three materials are finalized also

Revised Manuscript Received on 14 August, 2019.

Naveen Kumar K,Department of Aeronautical Engineering, Kumaraguru College of Technology, Coimbatore, Tamil Nadu,India. (Email: k.aeu@kct.ac.in)

Vijayanandh R, Department of Aeronautical Engineering, Kumaraguru College of Technology, Coimbatore, Tamil Nadu,India(Email: vijayanandh.raja@gmail.com)

Bruce Ralphin Rose J,Department of Aeronautical Engineering, Anna University Regional Campus, Tirunelveli, Tamil Nadu, India

Swathi V,Department of Aeronautical Engineering, Kumaraguru College of Technology, Coimbatore, Tamil Nadu,India.

NarmathaR ,Department of Aeronautical Engineering, Kumaraguru College of Technology, Coimbatore, Tamil Nadu,India.

Venkatesan $\mathbf{K}$, Department of Mechanical Engineering, AlagappaChettiar Government College of Engineering and Technology, Karaikudi, Tamil Nadu, India indented for various simulations. All the laminated cantilever structures are loaded with same boundary conditions in order to execute comparative study [2].

\section{REFERENCE COMPONENTS}

\section{Composite Materials}

Composite materials have the fundamental capability of advanced integrated effect with good clarity. Clarity provides the roué to their property estimations and thereby the composites are shortlisted according to the working environments. In this work, composite materials are suggested because of its load withstanding capability with light density [3].

\section{Structural Element - Beam}

Structural elements are classified based on the direction of load applied and geometrical property. When the structural element subjected to transverse load with high orientation in length, then that kind of element is referred to as beam element. The beam is one of the primary components involved in the fundamental study of structural engineering. Most of the complex real-time elements such as wind turbine, Aircraft wing, bridge are examples of beam element because of the availability of $\mathrm{V} \& \mathrm{~V}$ in beam theory. Generally, derivation and formulae are available for all types of beam problems but lack in the numerical simulation. Hence the research about beam and its implementation in the complex problems are emerging everywhere. Especially beam elements acting as a platform for emerging research areas such as piezoelectric power generation, fuel cells, etc [4]

\section{Applicable Domains}

Nowadays power extraction from piezoelectric material needs to be implemented in the suitable platforms because of the energy insufficient issue. In this article, two different real-time problems are considered as references to overcome their specification problems by the generation of renewable energy. The different domains are Aircraft wing and wind turbine blade.

\subsubsection{Aircraft Wing}

The design of the aircraft has to meet specific requirements which influence the complexity of its structure and the materials used in its construction. Different materials can also be used in the design of specific parts of

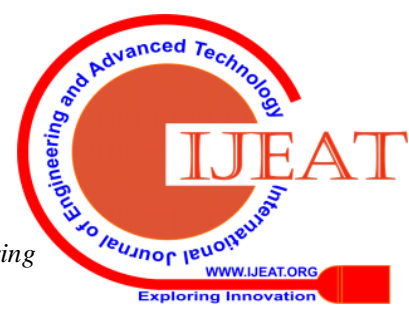


the aircraft, as a function of the initial requirements of the strength-to-weight ratio and the preferential directions of the applied loads. The wings of a modern aircraft can be designed as a combination of different types of materials as well as various types of elements, depending on their specific structural function. Steel and aluminum alloys can be used in the manufacture of ribs, whilst composite materials can be used in the design of the wing skin and the control surfaces [5].

\subsubsection{Wind turbine}

In recent years the wind turbine blade has been the subject of comprehensive study and research amongst all other components of the wind turbine. The blade material not only have to face large aerodynamic, inertial and fatigue loads but are now being designed to endure environmental effects such as Ultraviolet degradation of surface, accumulation of dust particles at sandy locations, ice accretion on blades in cold countries, insect collision on blades and moisture ingress. All these issues raise challenges for wind blade material used, its capacity to solve above-mentioned problems and also maintain its structural integrity. Hence, advanced composites are the best alternate solution for all the issues of a wind turbine [6].

\section{PROBLEM SOLUTION TECHNIQUES - NUMERICAL SIMULATION}

The simulation was run using the FEA method in ANSYS Workbench 16.2 in which totally two varieties of analysis were completed. To estimate the power, the theoretical formula needs two inputs, which are natural frequency and displacement hence modal, FSI analyses were finalized. Both analyses were executed for three different composite materials [7].

\subsection{Fluid-Solid Interaction (FSI)}

FSI is the non-stationary coupling between a fluid flowing through the flexible mechanical structure. During the computation of FSI problems, the flexible structure and fluid models are required to interface. A few years ago these computational techniques were too difficult, expensive and unthinkable due to unavailability of soft skill, which has turned round to awaken an interest in fluid-structure interaction presently. This awareness is owed to the development in a field of aerospace engineering, aerodynamics, and computational fluid dynamics. In the numerical simulation, the prediction accuracy is based on the suitable boundary conditions applied, efficient discretization by capture the critical design and involvement of core formulae. Major challenging task in computational simulation is to estimate the parameters, which are very close to experimental data such as stress, deformation, etc in the case of structural analysis and velocity, pressure, etc in the case of flow analysis. In the computational simulation, the application of advanced techniques such as FluidStructure Interaction, moving reference approach, explicit analysis, APC composite analysis is the smartest way to predict the exact values, which gives a low error percentage with a high probability of reliability [8]. In this paper suggest that design and its optimization of a beam structure with the inclusion FSI while it's flying. This idea may create the basic concept behind the design and lifetime of the beam element to the designer. In this paper, FSI has been used on beam element such as aircraft wing, wind turbine blade, etc to effectively predict the structural parameters, due to fluid impact load while undergoes the high-speed operation. The prediction methodology of FSI has been divided into two groups, which are one-way coupling and two-way coupling. In one-way coupling, the fluid analysis has been solved separately as per the given boundary conditions and then thereby the results are imported in structural analysis as one of the boundary conditions. In two-way coupling, the boundary conditions of the fluid analysis and structural analysis have been individually after that the consolidated settings have been integrated into the FSI simulation tool [9].

\section{1.1 Two-way Coupling Analysis}

In this paper, two-way coupling methodologies has been used with the help of Ansys Workbench 16.2. Two-way coupling is better performer compared to one-way coupling due to its computing structures. Two-way coupling FSI analysis results primarily depend upon the finite element capture on the beam structure. 3D tetrahedral element has been chosen because of wing geometry criticality [10]. Major systems of the two-way coupling FSI analysis in the Ansys Fluent 16.2 are the fluid flow Fluent system, structural system, and FSI coupling system. The fluid system comprises of geometry, Mesh, Setup, Solution; in which boundary conditions take place under the Setup menu. In boundary conditions, k-omega has been chosen as turbulence model and turbulence specification method is selected as intensity \& viscosity ratio, in which intensity is given as $5 \%$ and viscosity is given as $10 \%$ to predict the result effectively. Solution method of this flow analysis has been selected as a coupled formulation with hybrid initialization because of the availability of self-test verification. In our beam element has a lot of critical design so second-order to upwind methodologies has been selected as spatial discretization gradient. The structural system of workbench has been comprising of engineering data, geometry, mesh, setup and solution, in which engineering data plays a vital role among other subsystems. All types of material properties are inserted in the structural analysis through engineering data. FSI coupling system is comprised of setup and solution, in which setup is used to integrate the fluid flow setup and structural setup thereby the execution takes place for numerical results [11].

\subsubsection{Beam Element}

This article deals with the material optimization on beam element for increasing the lifetime with the help of numerical simulation. To make approximate solution into an acceptable solution, beam element has been used, which is a horizontal member subjected vertical loads and bending moments. Based on the degree of freedom (DOF) count the bam element classified into two types, which are normal loading conditions (6 DOF) and pure bending conditions (4 DOF). 


\subsubsection{Types of Materials}

Different types of materials were implemented in our reference component such as Aluminium, steel, wood, etc. but the advanced one is composite implementation, in which the material selection usually depends on its modulus of elasticity, Poisson's ratio, the coefficient of thermal expansion and density. In our simulation, three materials are employed, which are GFRP, CFRP, and Kevlar. The properties are obtained from the literature [12].

\subsubsection{Modeling Discretization}

A physical model is converted into the finite element model, which is called discretization to observe structural behavior. The physical model cannot react to external load but finite elements perfectly obey the applied load hence the discretization process is mandatory for problem-solving using numerical simulation. In discretization nodes and elements are the fundamental components, which support the achievement of full coverage on the physical model. To get high accrued results components of the physical model are strongly replaced by the finite element components.

\subsubsection{Loads in a FSI}

Pressure, heat flux, rpm, velocity, and gravity are the different types of major input loading environments in FSI, which make FSI as more complex problems in the perspective of calculation. Excitation velocity $(83 \mathrm{~m} / \mathrm{s})$ is given as input velocity for this flow simulation, which helped for harmonic analysis. Modal analysis is estimated here, with the help of the density of the materials.

\subsection{Modal Analysis}

Frequency estimation is classified into two categories, which are modal and harmonic. Free vibrational analyses are coming under modal analyses and harmonic analyses are capable to solve forced vibrational problems. In this paper, modal analysis has been used as one of the supporting techniques for theoretical power extraction. Modal analysis generally depends upon the density of the material and supports of the object. Density of the material plays a vital role in the construction of the mass matrix, which predominantly used for natural frequency estimation.

\subsection{Results}

\subsubsection{CFRP - FSI}

\subsubsection{Aeroplane wing - FSI Result}

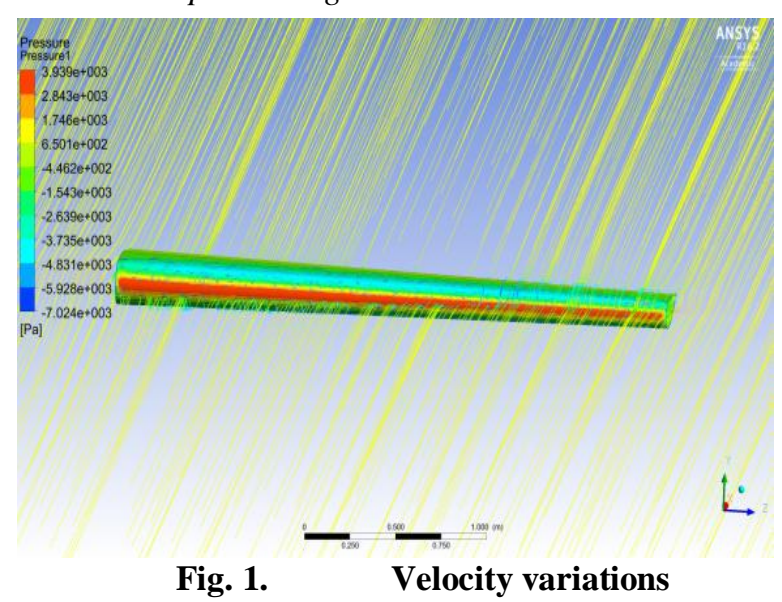

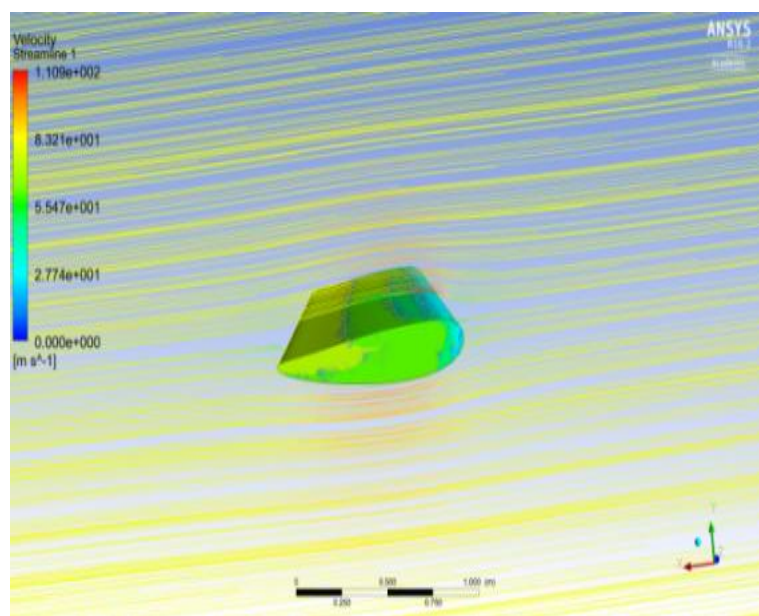

Fig. 2. Pressure variations

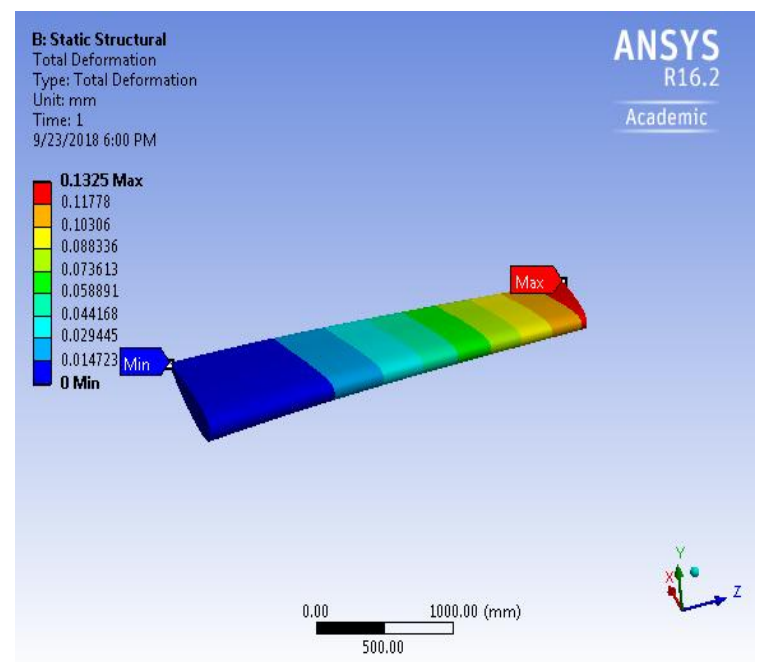

Fig. 3. Deformation

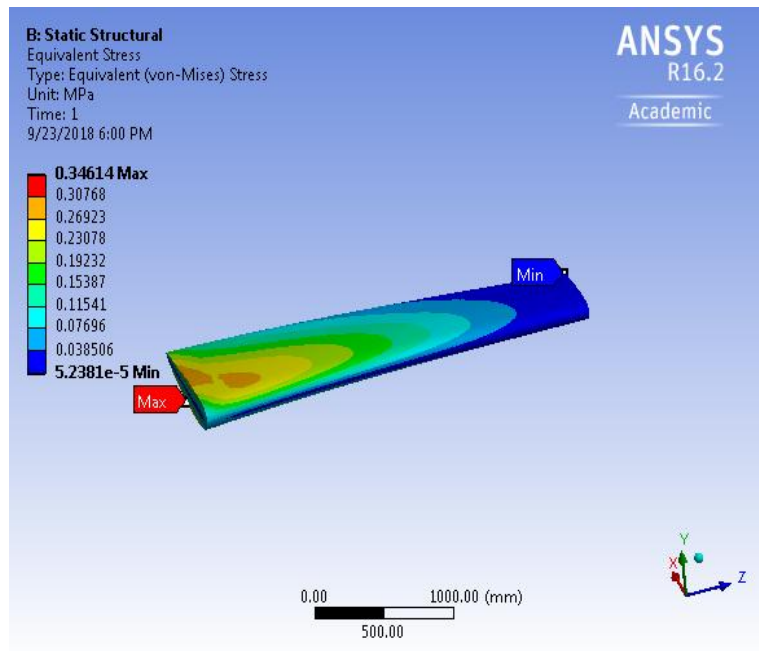

Fig. 4. Stress Variation

Figures 1 to 4 shows the FSI simulation results of aeroplane wing, which has the $5 \mathrm{~m}$ length.

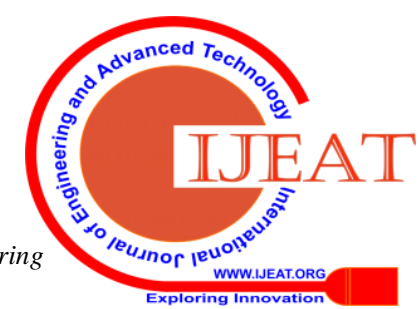




\subsubsection{Aeroplane wing - Modal Analysis}
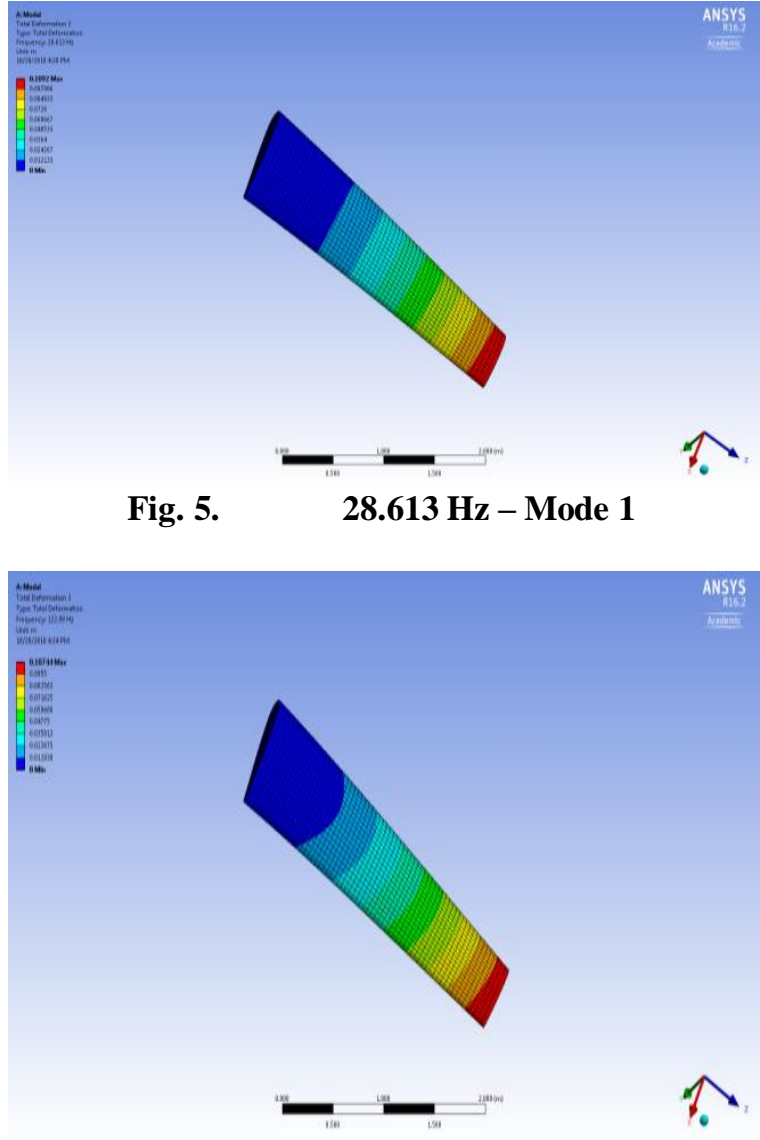

Fig. 6.

122.99 Hz - Mode 2

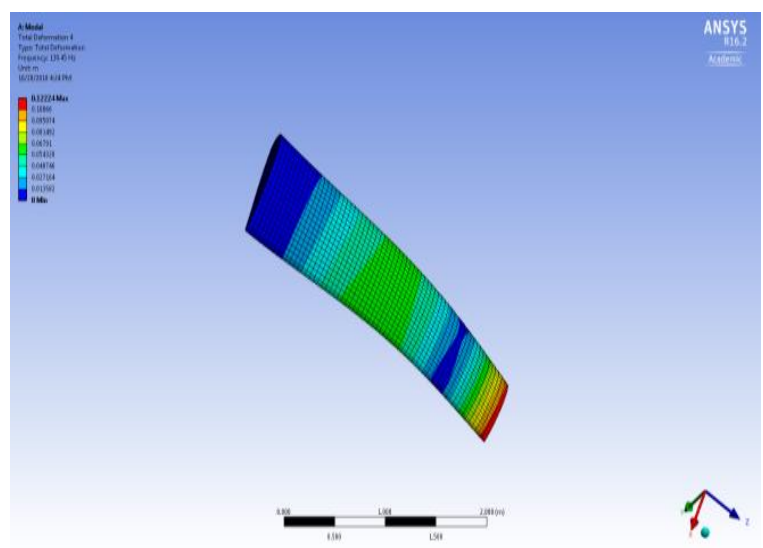

Fig. 7. $\quad 130.45 \mathrm{~Hz}-$ Mode 3

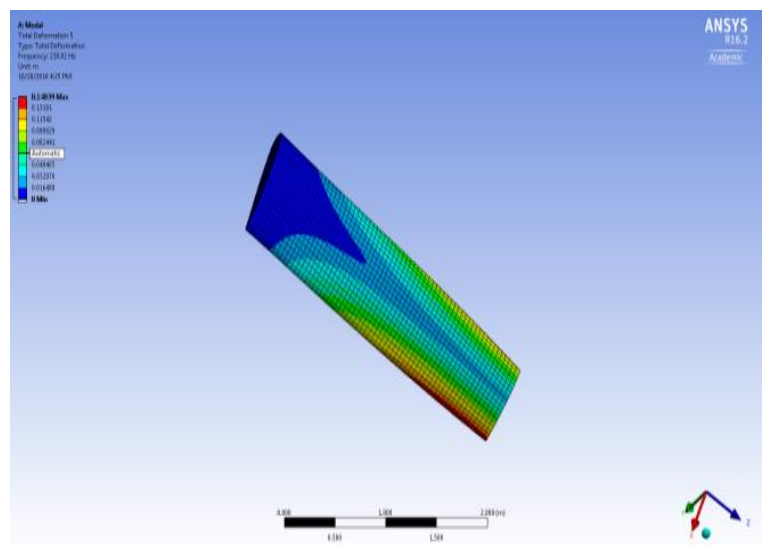

Fig. 8.

230.82 Hz - Mode 4

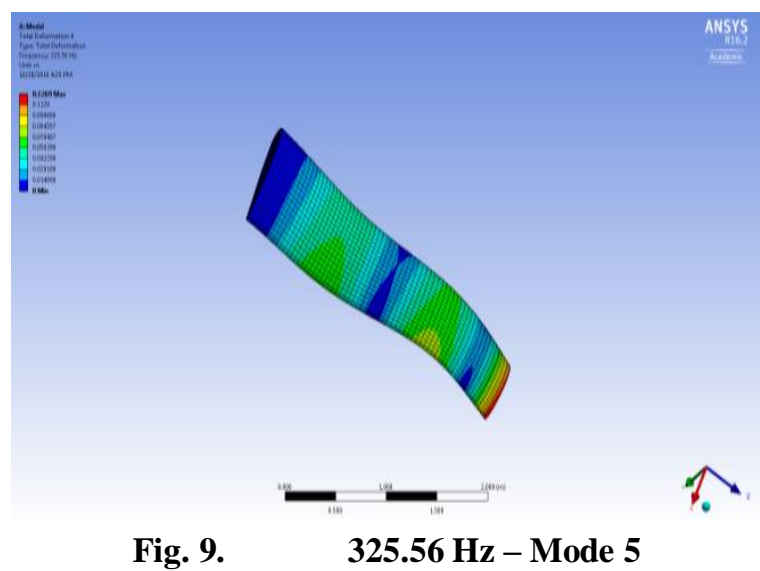

Figures 5 to 9 shows the mode shapes of aeroplane wing for the given boundary conditions.

\subsubsection{Unmanned Aerial Vehicle (UAV) wing-FSI}
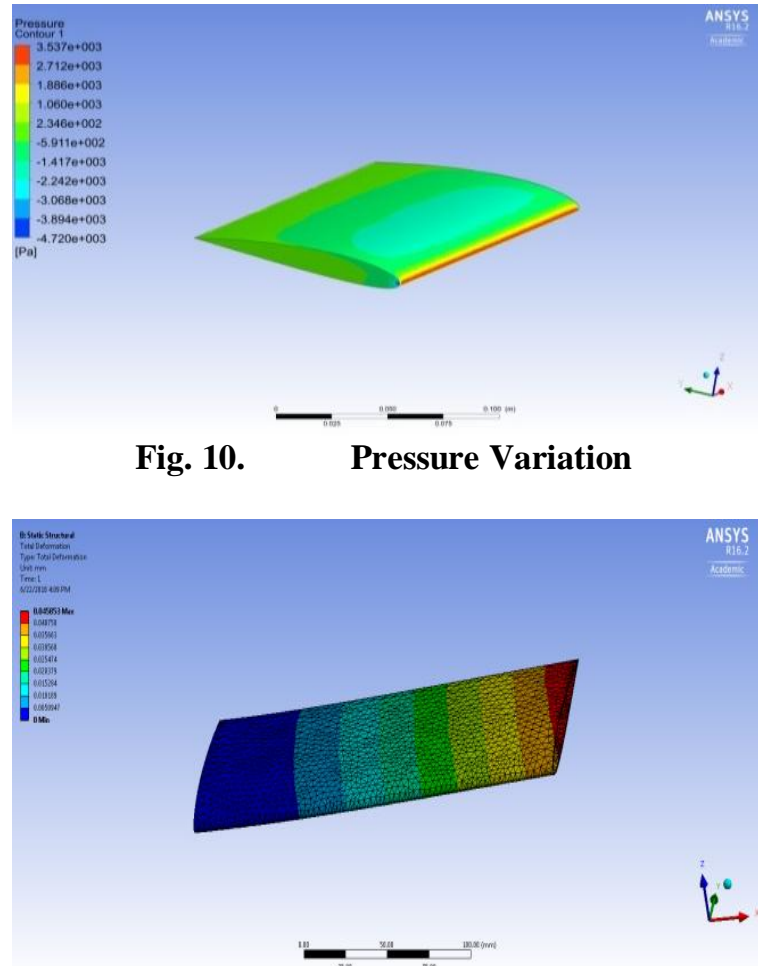

Fig. 11. Total Deformation

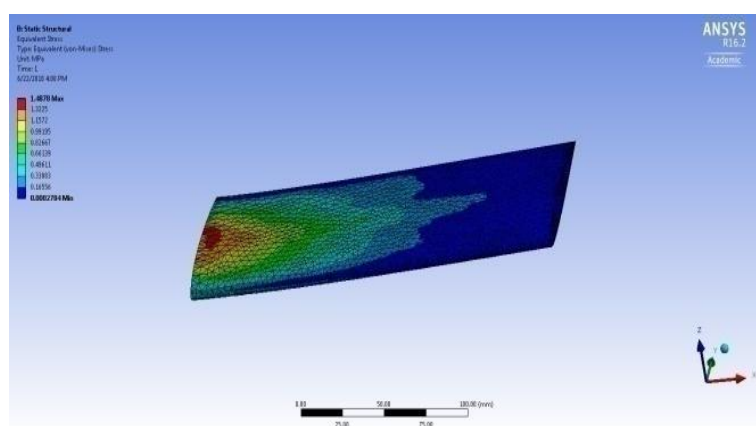

Fig. 12. Equivalent Stress

Figures 10 to 12 show the FSI simulation results of UAV wing, which has the $30 \mathrm{~cm}$ length.

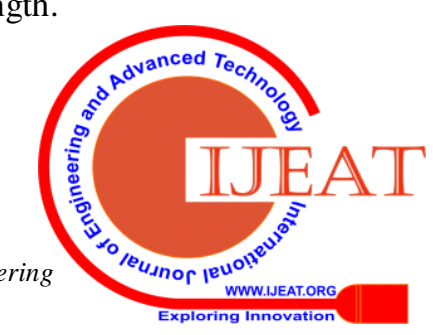




\subsubsection{UAV wing - Modal Analysis}

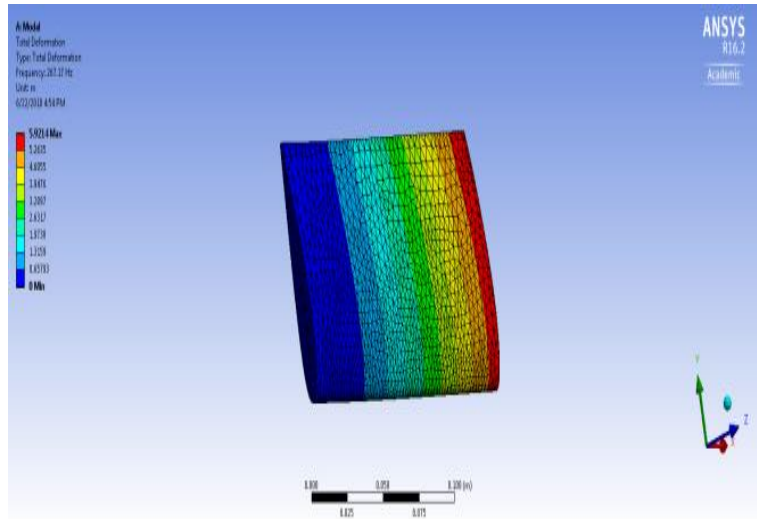

Fig. 13. $\quad 267.17 \mathrm{~Hz}-$ Mode 1

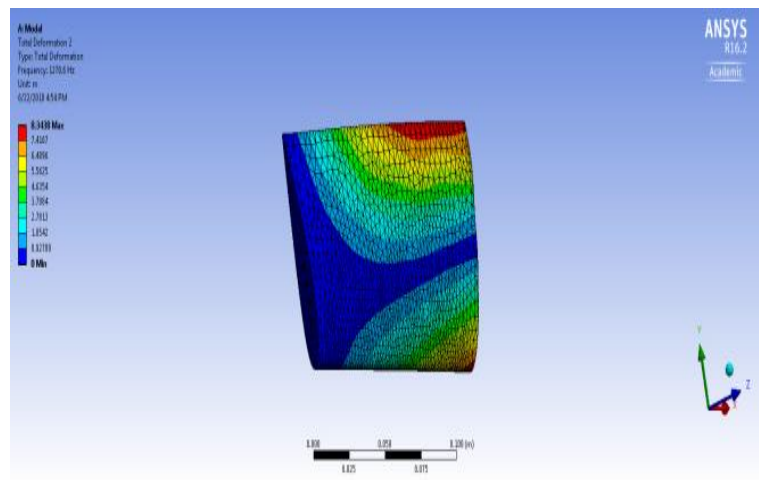

Fig. 14. $\quad 1270.6 \mathrm{~Hz}-$ Mode 2

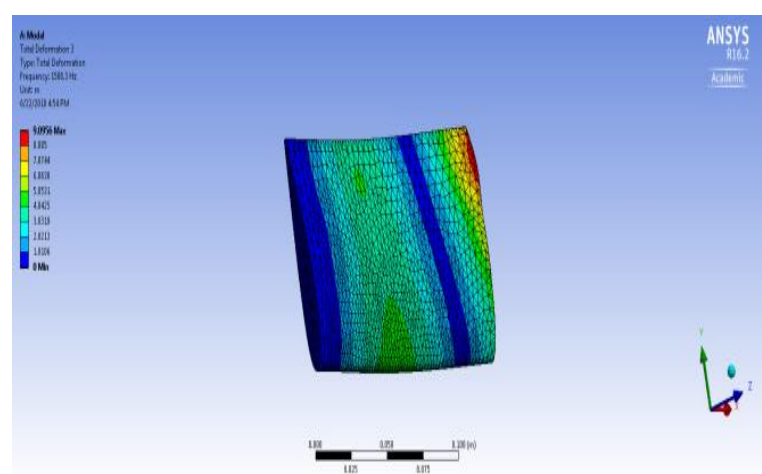

Fig. 15. $\quad 1588.3 \mathrm{~Hz}$ - Mode 3

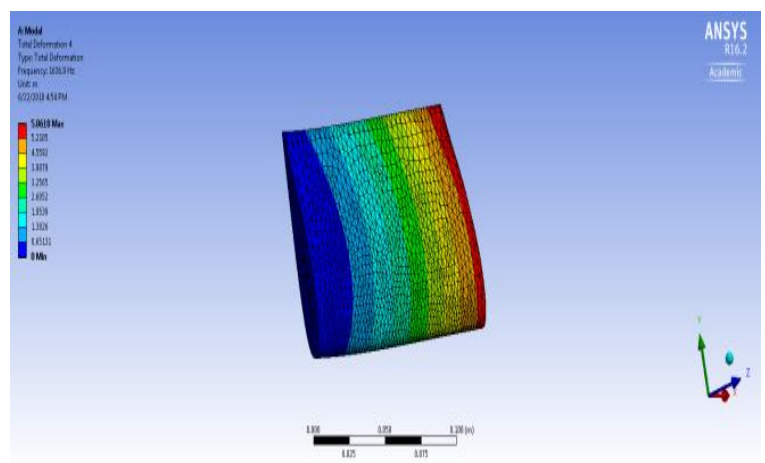

Fig. 16. $\quad 1636.9 \mathrm{~Hz}-$ Mode 4

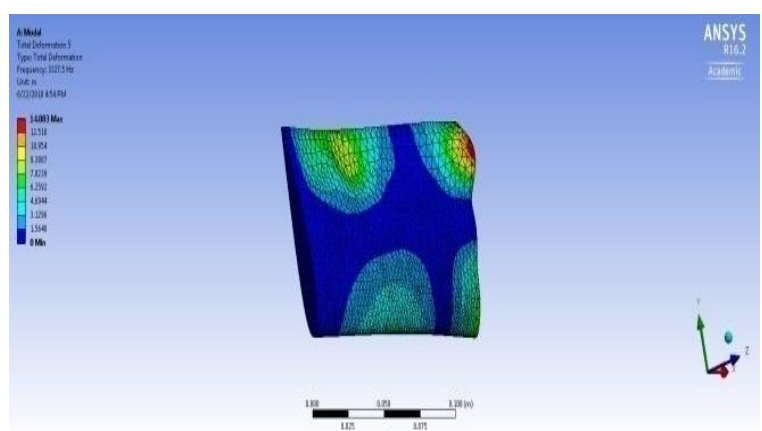

Fig. 17. $\quad 3327.5 \mathrm{~Hz}$ - Mode 5

Figure 13 to 17 shows the mode shapes of UAV wing with different end support condition.

\subsubsection{Wind Turbine Blade - FSI Result}

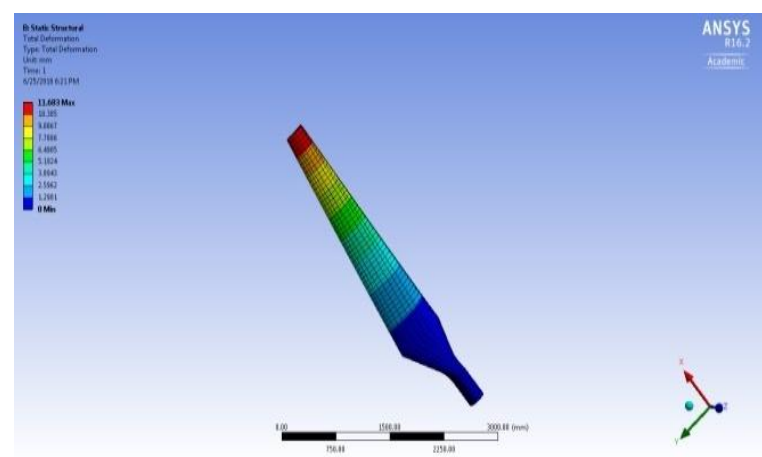

Fig. 18. Total Deformation

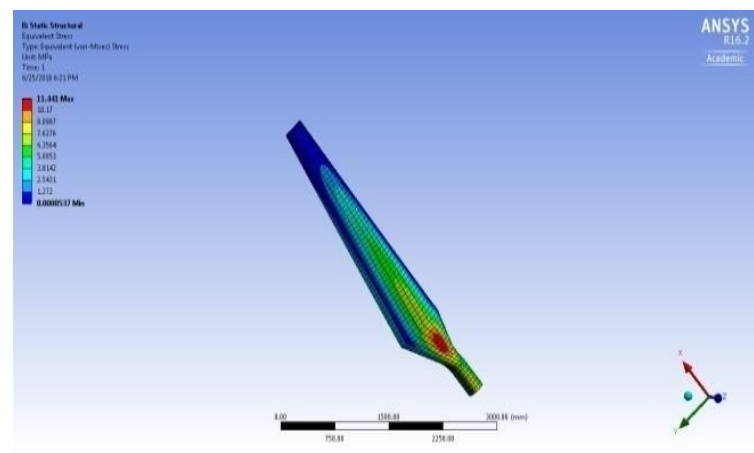

Fig. 19. Stress plot of a blade

Figure 18 and 19 shows the FSI simulation results of wind turbine blade, in which the excitation velocity is considered as primary input.

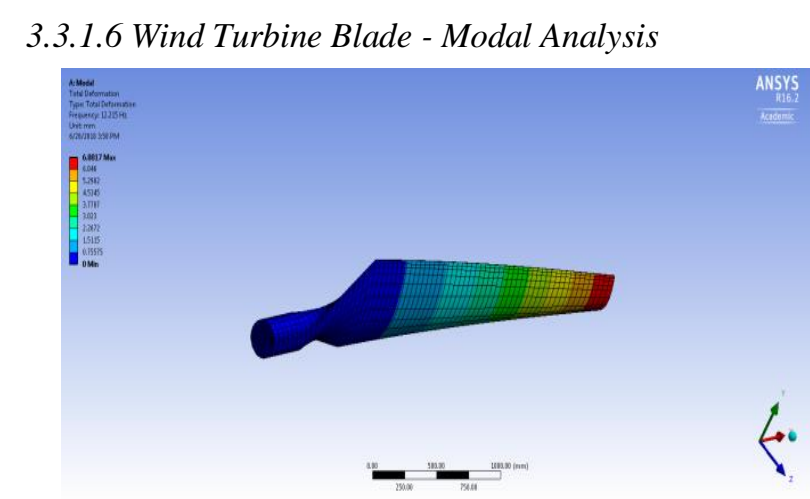

Fig. 20.

12.215 Hz - Mode 1

Published By:

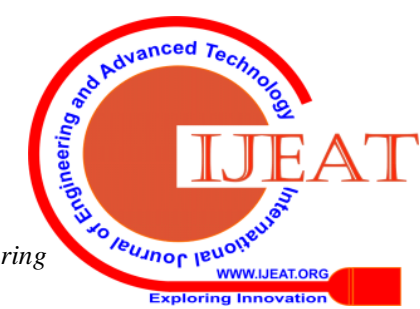


Research on Structural behavior of Composite Materials on different Cantilever Structures using FSI

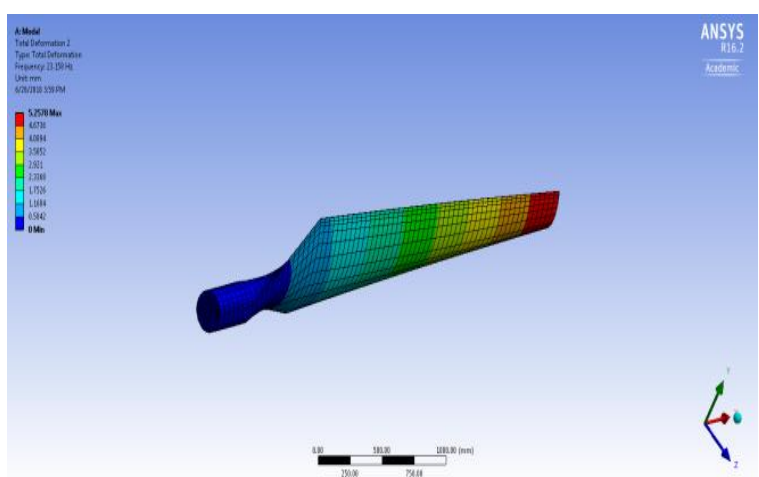

Fig. 21. $\quad 23.158 \mathrm{~Hz}-$ Mode 2

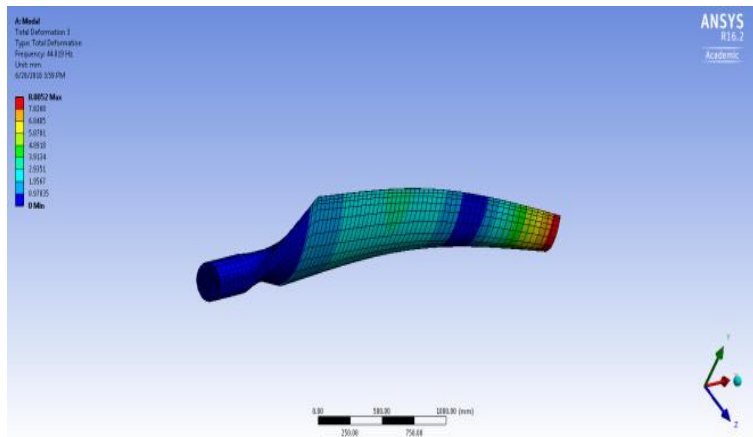

Fig. 22. $\quad 44.109 \mathrm{~Hz}-$ Mode 3

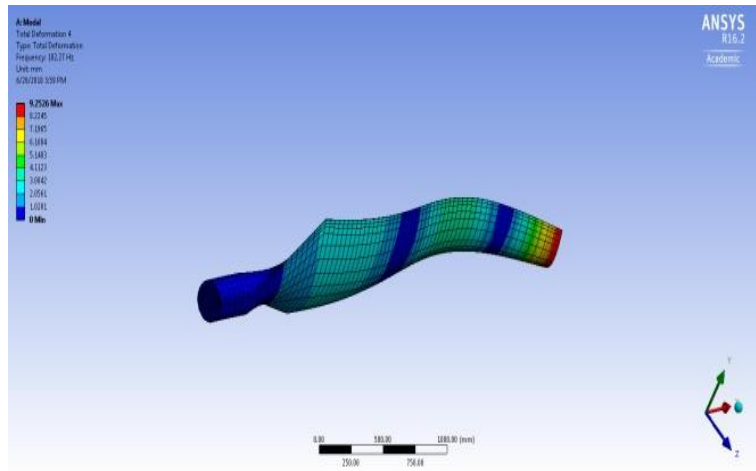

Fig. 23. $\quad 102.27 \mathrm{~Hz}-$ Mode 4

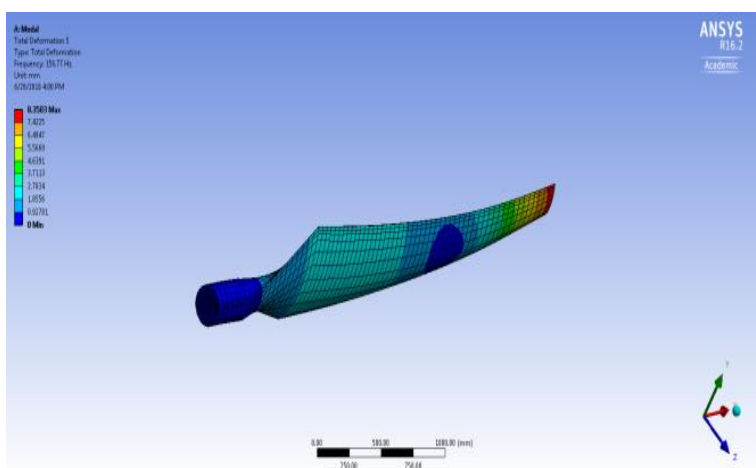

Fig. 24. $\quad 157.77 \mathrm{~Hz}$ - Mode 5

Figures 20 to 24 shows the mode shapes of wind turbine blade for the given boundary conditions.

3.3.2.1 Aeroplane wing - FSI Result

\subsubsection{GFRP}

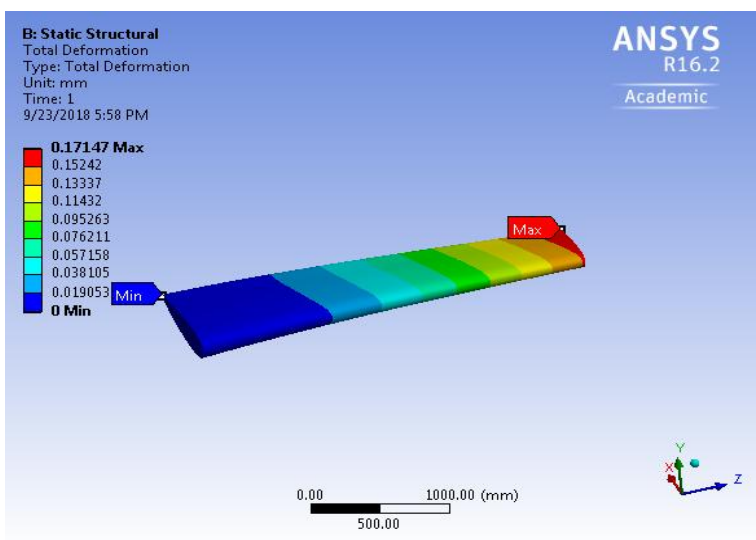

Fig. 25. Total Deformation

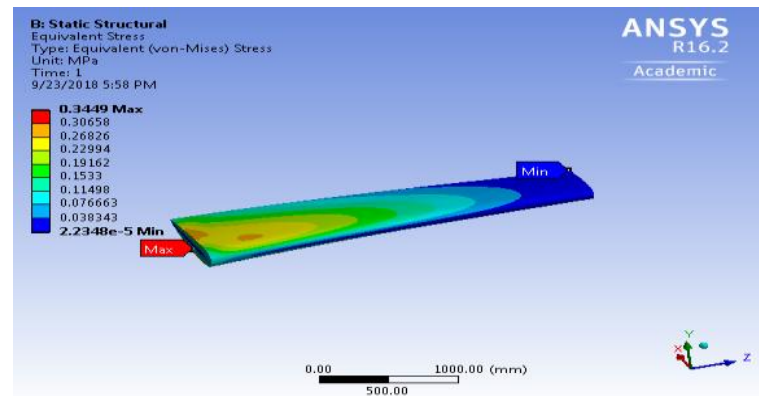

Fig. 26. Stress variation

Figure 25 and 26 shows the deformation variation throughout the aeroplane wing, which is discretized with GFRP property.

\subsubsection{Aeroplane wing - Modal Analysis}

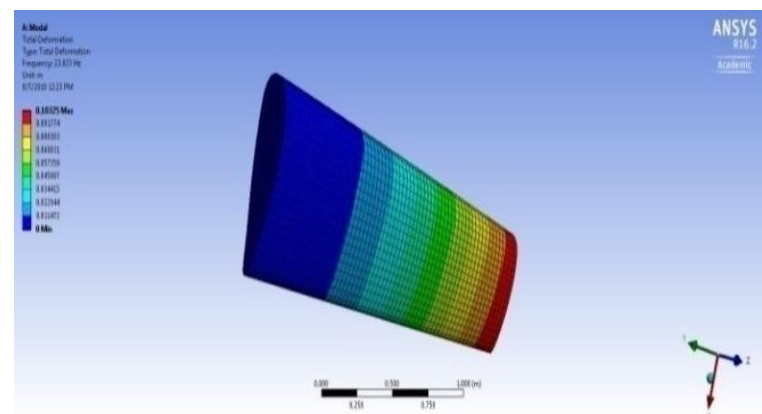

Fig. 27. $\quad 23.823 \mathrm{~Hz}-$ Mode 1

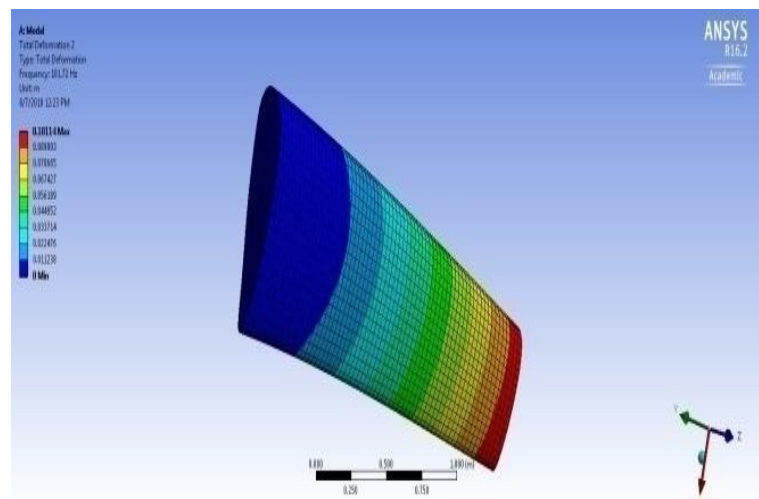

Fig. 28. $\quad 101.72 \mathrm{~Hz}-$ Mode 2

Published By:

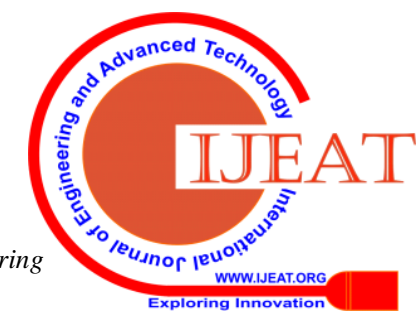




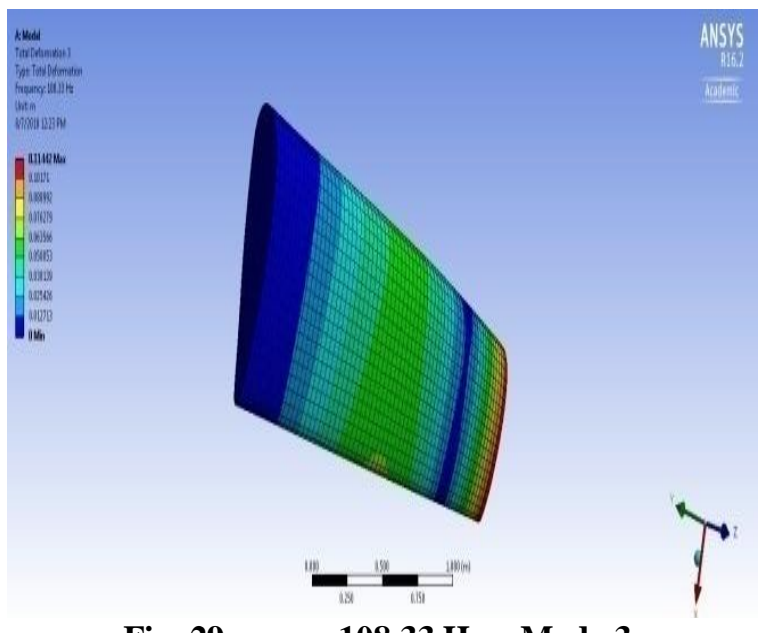

Fig. 29. $\quad 108.33 \mathrm{~Hz}-$ Mode 3

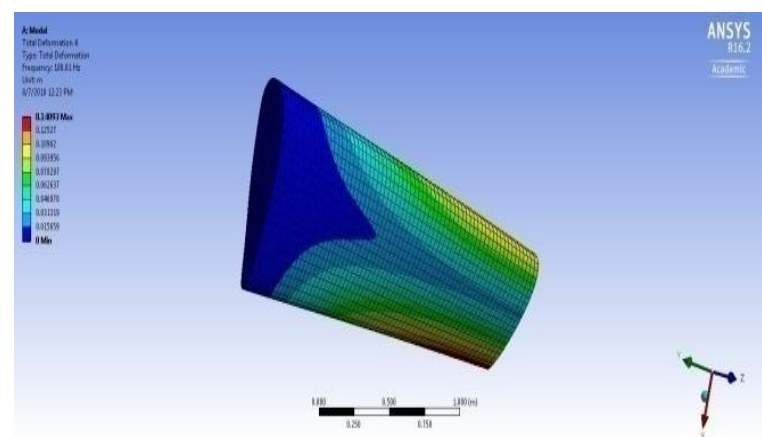

Fig. 30. $\quad 180.01 \mathrm{~Hz}-$ Mode 4

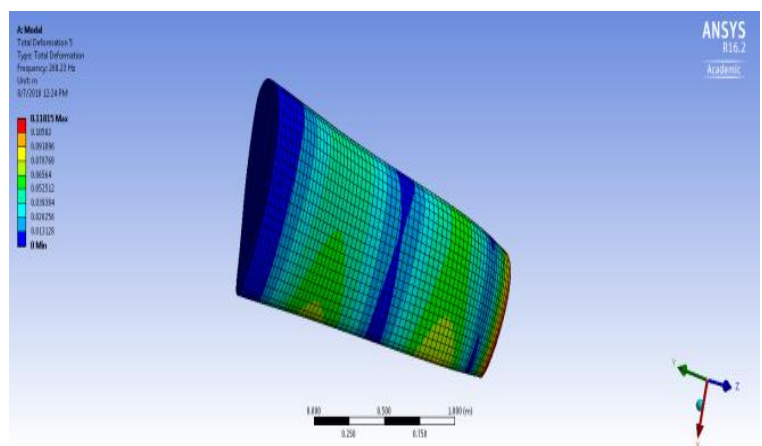

Fig. 31. $\quad 269.23 \mathrm{~Hz}$ - Mode 5

First five mode shapes of GFRP aeroplane wing have been extracted, which are shown in the Figures 27 to 31.

\subsubsection{UAV wing - FSI Result}

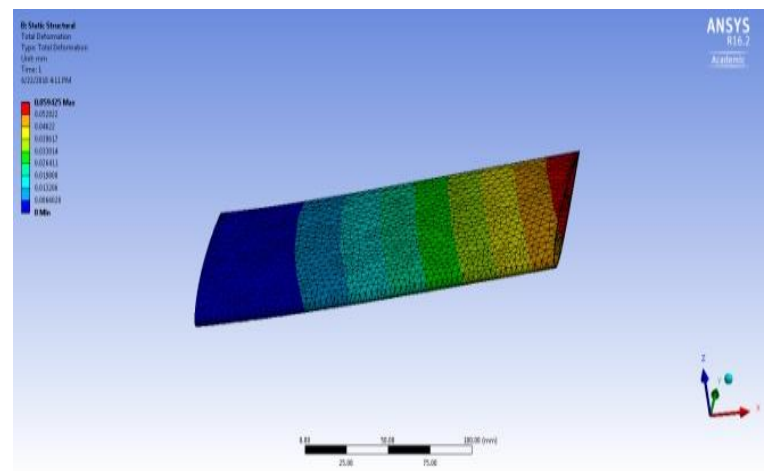

Fig. 32. Total Deformation

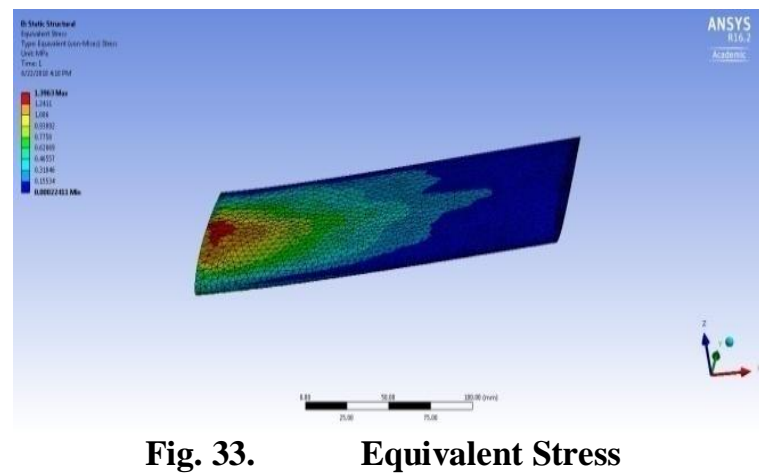

Figure 32 and 33 reveals the structural variations of UAV wing, which is assigned the property of GFRP.

\subsubsection{UAV wing - Modal Analysis}

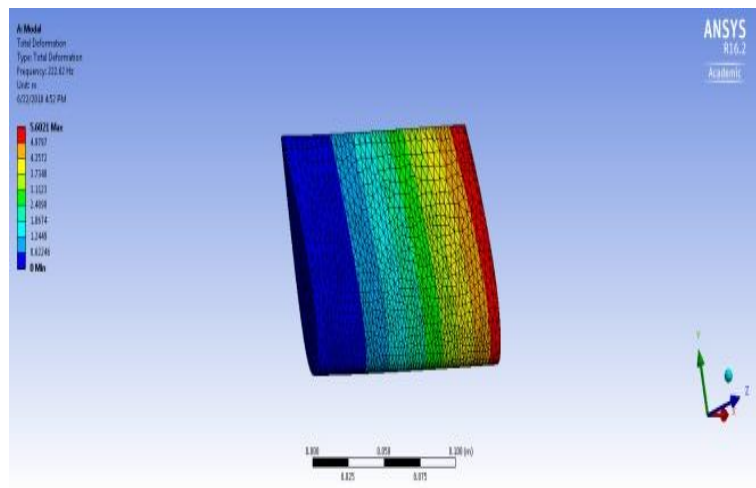

Fig. 34. $\quad 222.62 \mathrm{~Hz}-$ Mode 1

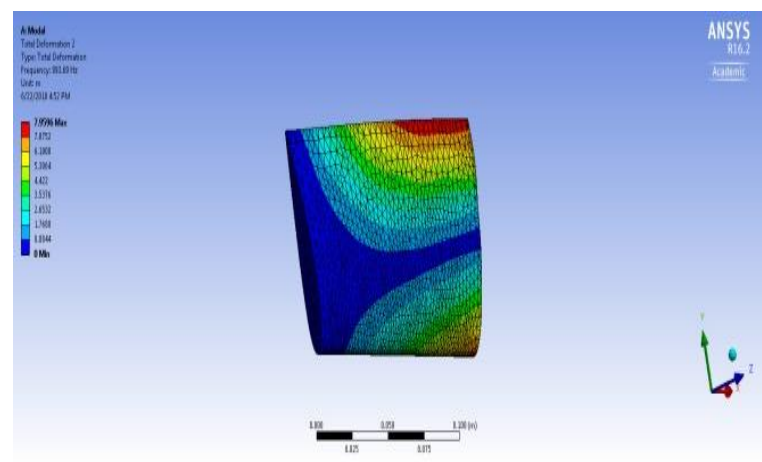

Fig. 35. $\quad 993.69 \mathrm{~Hz}-$ Mode 2

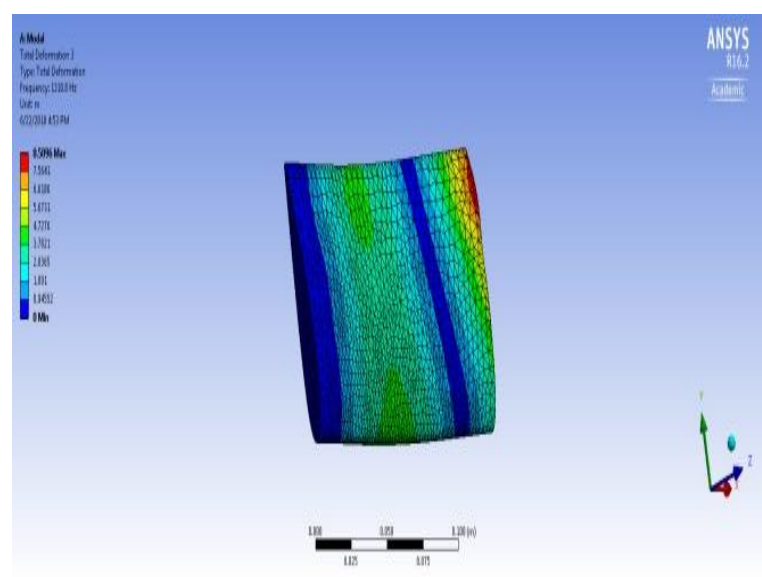

Fig. 36. $\quad 1310.8 \mathrm{~Hz}-$ Mode 3

\section{.}




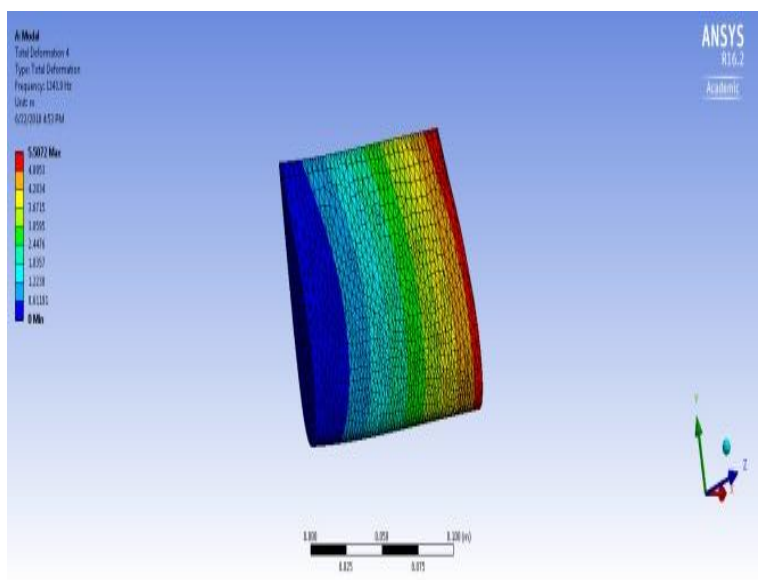

Fig. 37. $\quad$ 1343.9 Hz- Mode 4

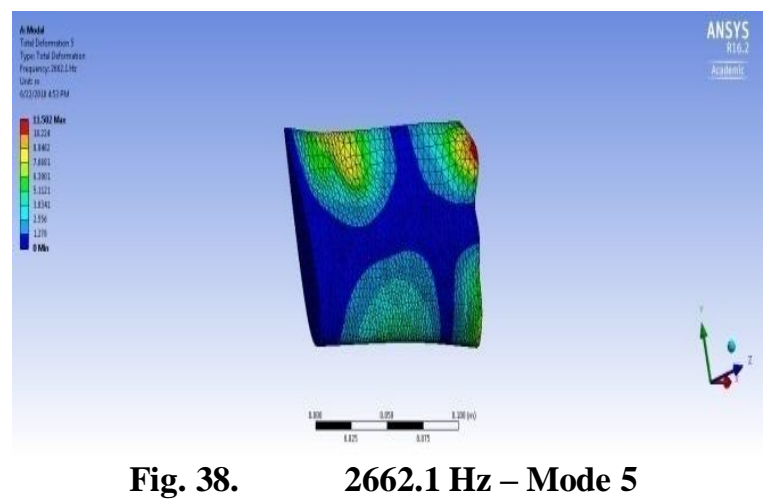

First five mode shapes of GFRP UAV wing have been extracted, which are shown in the Figures 34 to 38.

\subsubsection{Wind Turbine Blade - FSI Result}
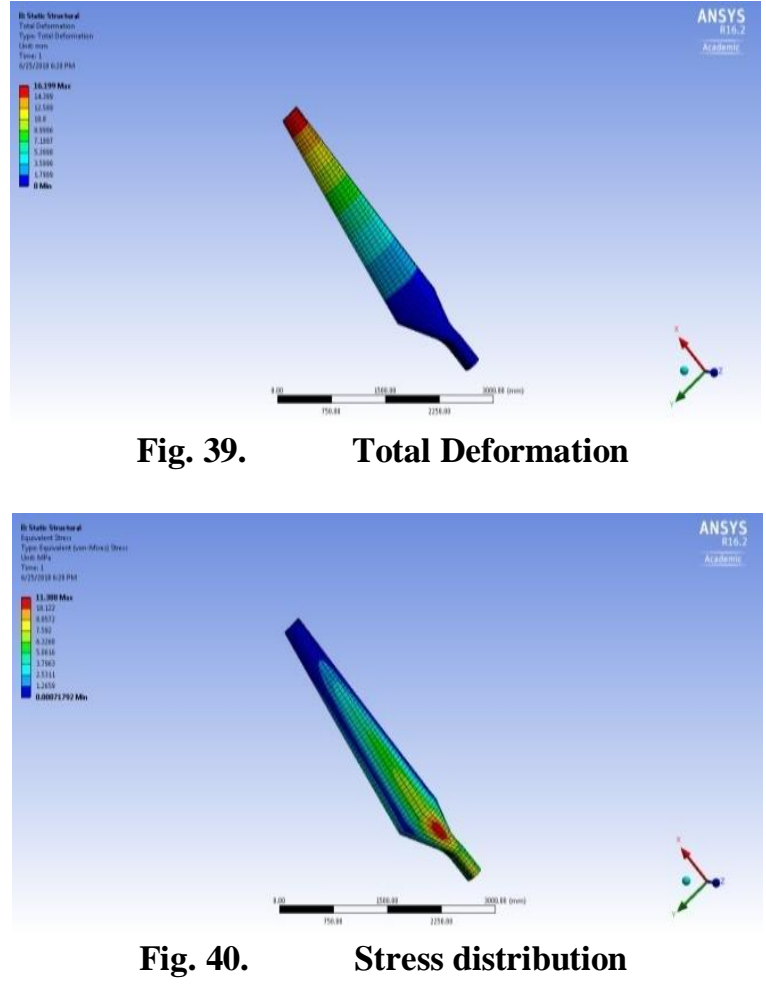

For the given excitation velocity, the deformation and stress variations are predicted, which are shown in the figure 39 and 40 respectively.

\subsubsection{Wind Turbine Blade - Modal Analysis}

Modal analysis of wind turbine blade have been completed with the help of Ansys Workbench 16.2, in which five mode shapes are selected and predicted and thereby reveled in the figures 41 to 45 .

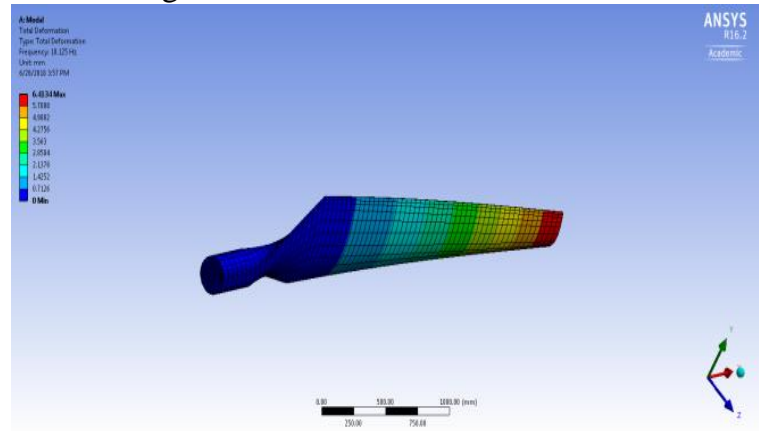

Fig. 41. $\quad 10.125 \mathrm{~Hz}-$ Mode 1

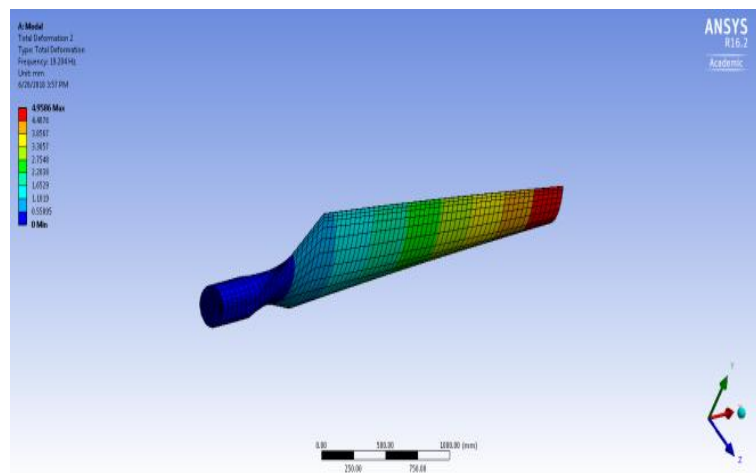

Fig. 42. $\quad 19.204 \mathrm{~Hz}$ - Mode 2

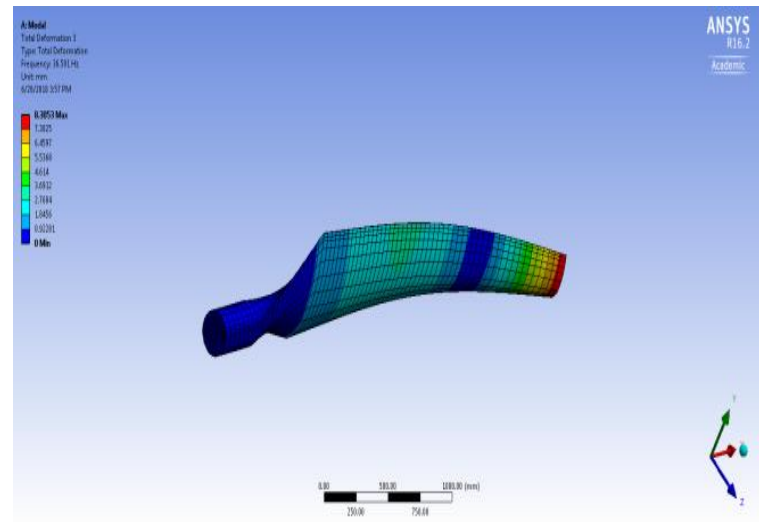

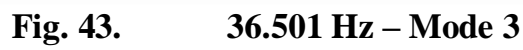

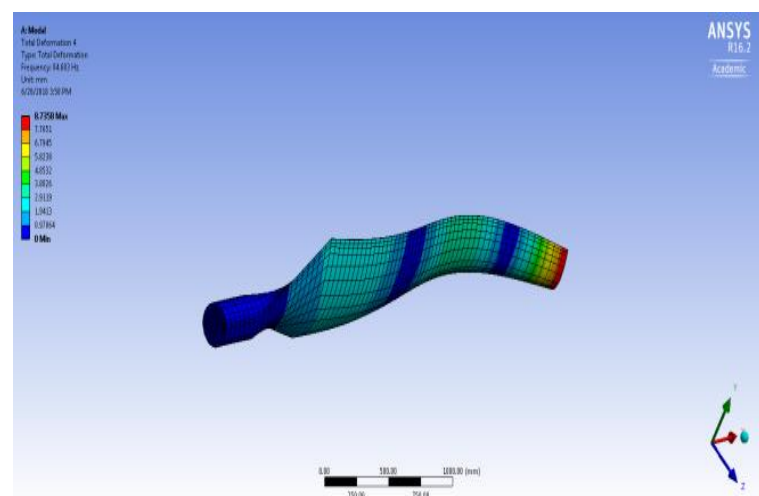

Fig. 44. $\quad$ 84.683 Hz-Mode 4

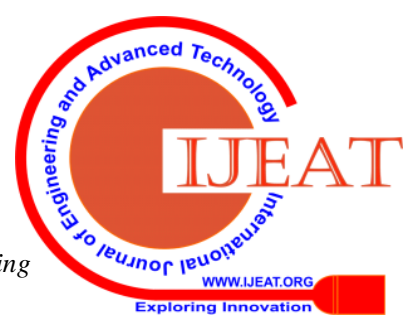




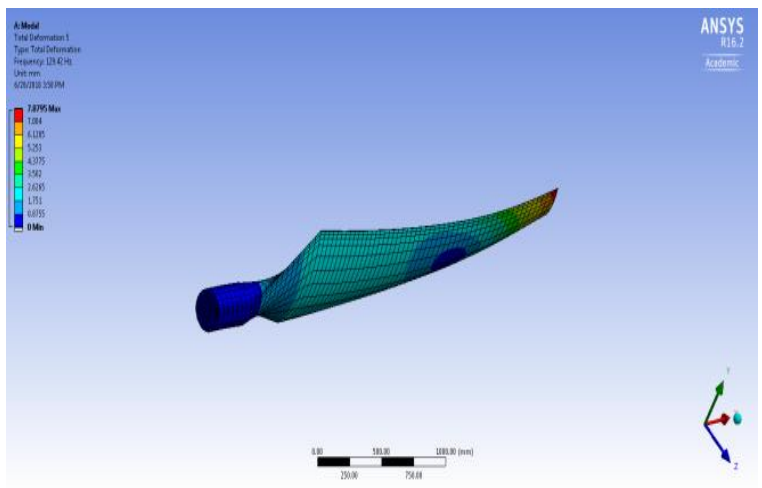

Fig. 45. $\quad 129.42 \mathrm{~Hz}-$ Mode 5

\subsubsection{Kevlar}

\subsubsection{Aeroplane wing - FSI Result}

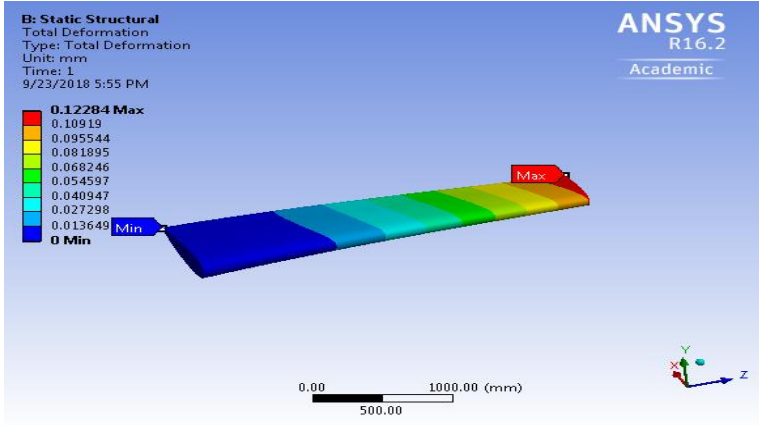

Fig. 46. Total Deformation

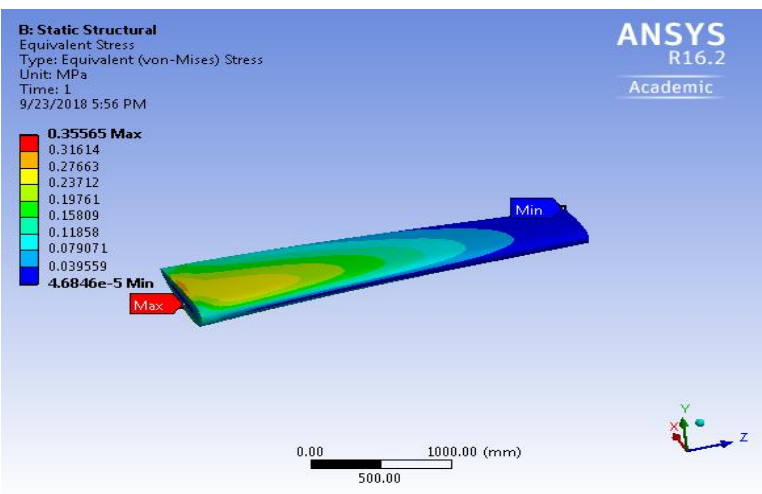

Fig. 47.

Stress

FSI simulations are predicted for the different end conditions as well as excitation velocity input. The important structural parameters revealed in the figures 46 and 47.

\subsubsection{Aeroplane wing - Modal Analysis}

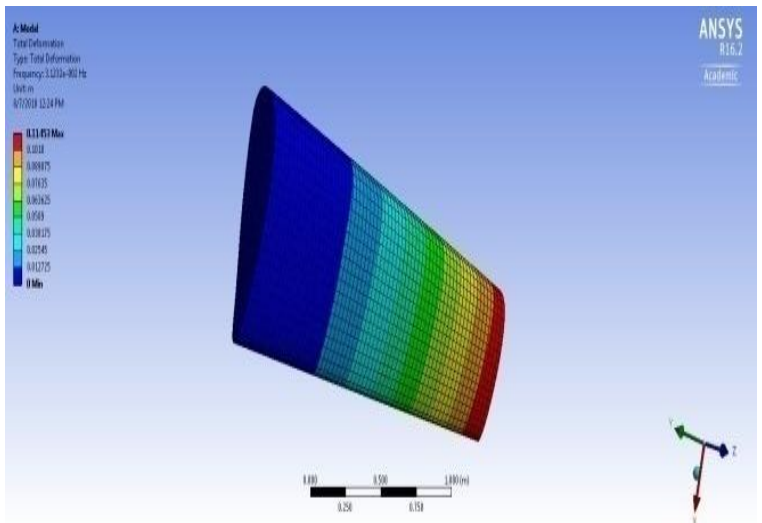

Fig. 48.

31.123 Hz - Mode 1

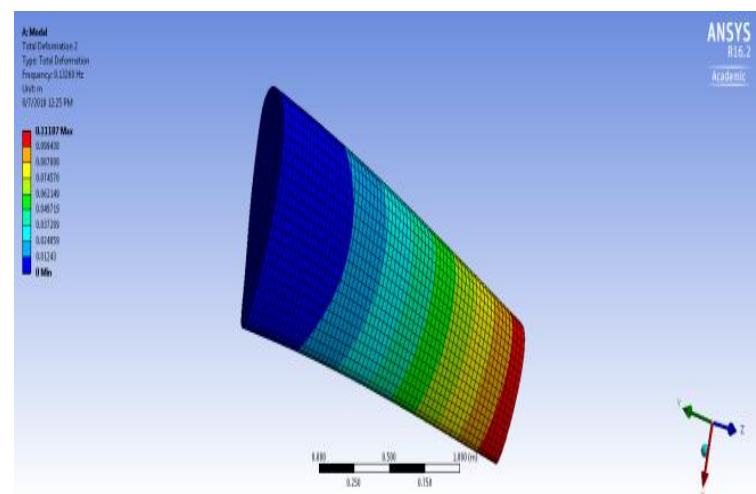

Fig. 49. $\quad 132.69 \mathrm{~Hz}-$ Mode 2

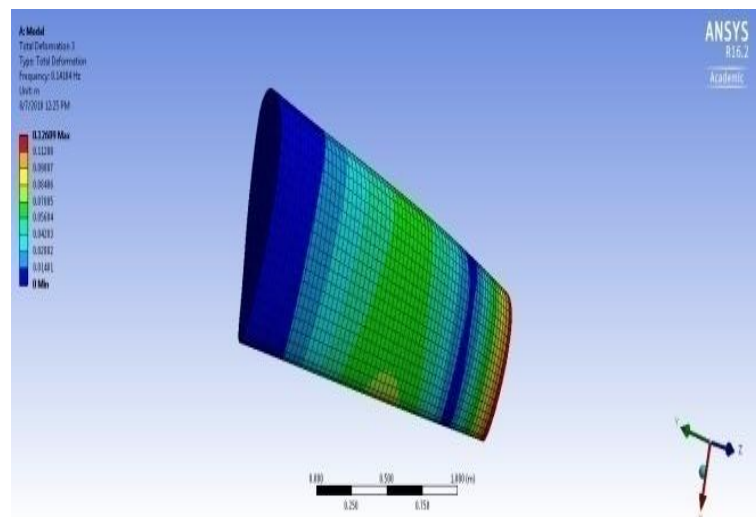

Fig. 50. $\quad 141.84 \mathrm{~Hz}-$ Mode 3

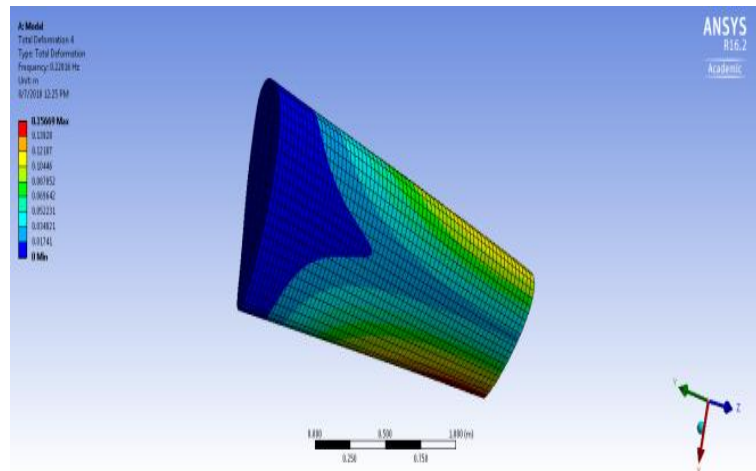

Fig. 51. $\quad 228.16 \mathrm{~Hz}-$ Mode 4

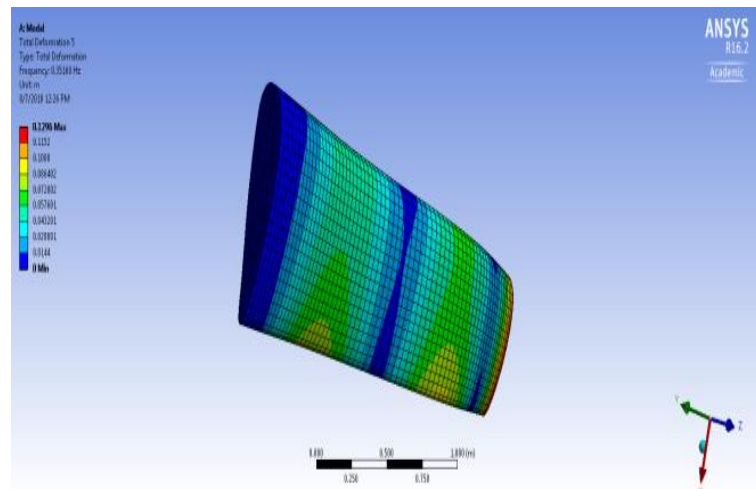

Fig. 52. $\quad 351.69 \mathrm{~Hz}-$ Mode 5

Figures 48 to 52 shows the mode shapes of aeroplane wing for the given boundary conditions such as fixed support at one end and free end is other end.

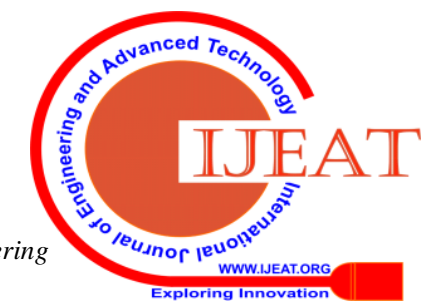




\subsubsection{UAV wing - FSI Result}

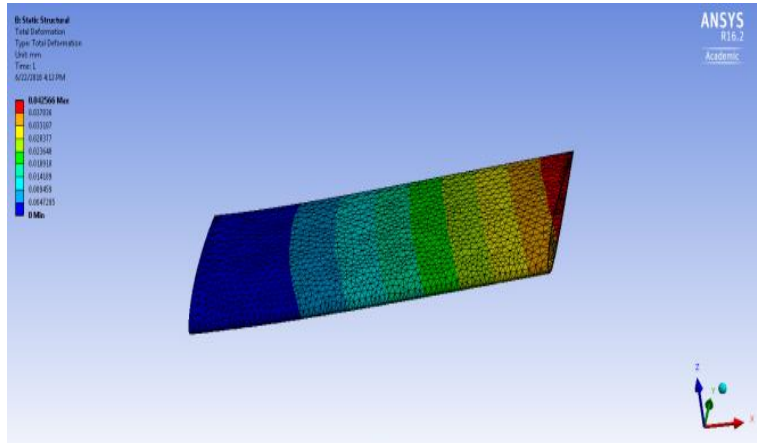

Fig. 53. Total Deformation

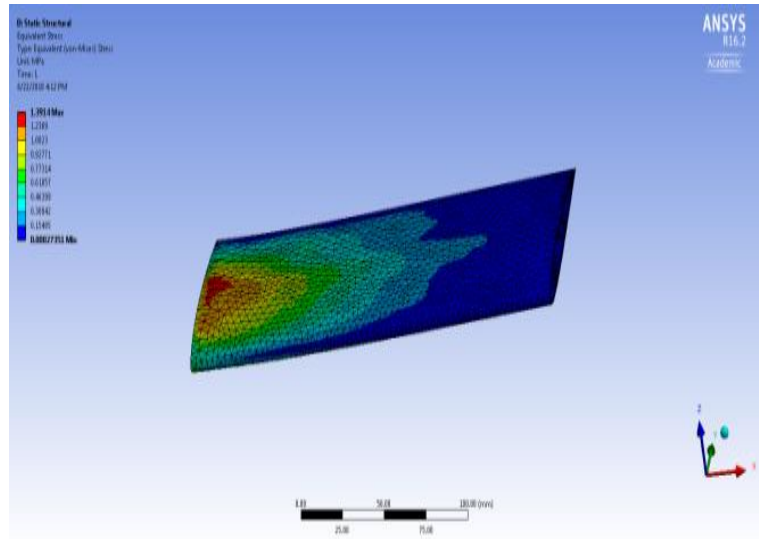

Fig. 54. $\quad$ Equivalent Stress

Figure 53 and 54 shows the FSI simulations results of UAV wing, in which deformation and stress plays vital role.

\subsubsection{UAV wing - Modal Analysis}

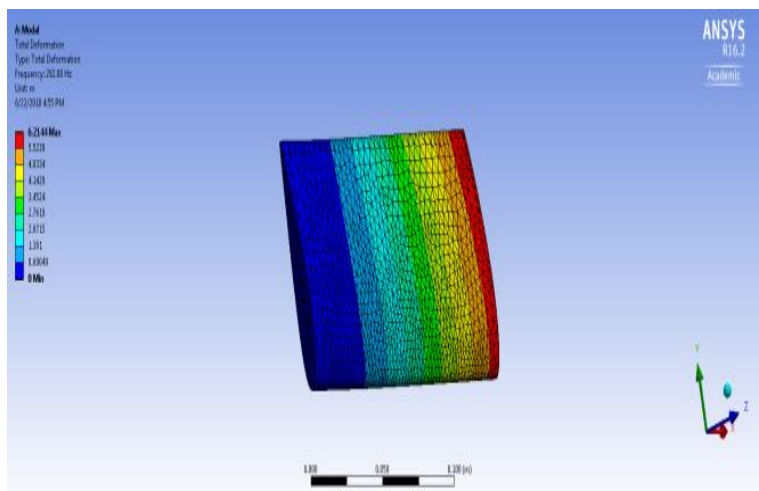

Fig. 55. $\quad 292.08 \mathrm{~Hz}-$ Mode 1

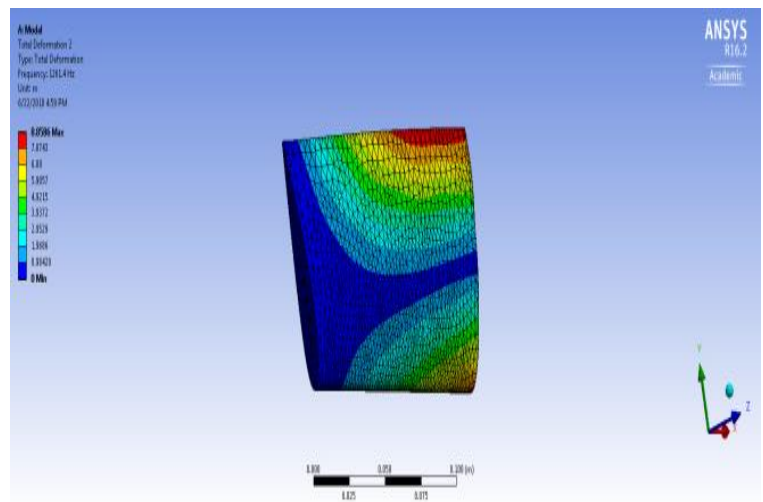

Fig. 56. $\quad 1261.4 \mathrm{~Hz}-$ Mode 2

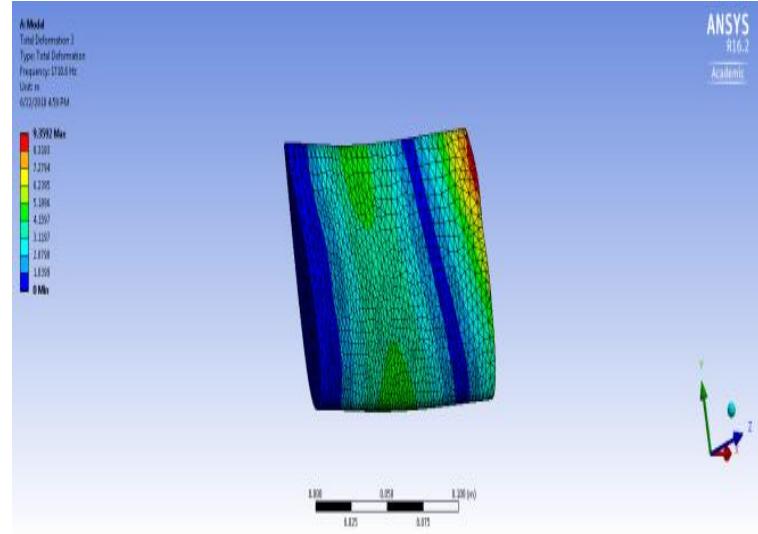

Fig. 57. $\quad 1710.6 \mathrm{~Hz}$ - Mode 3

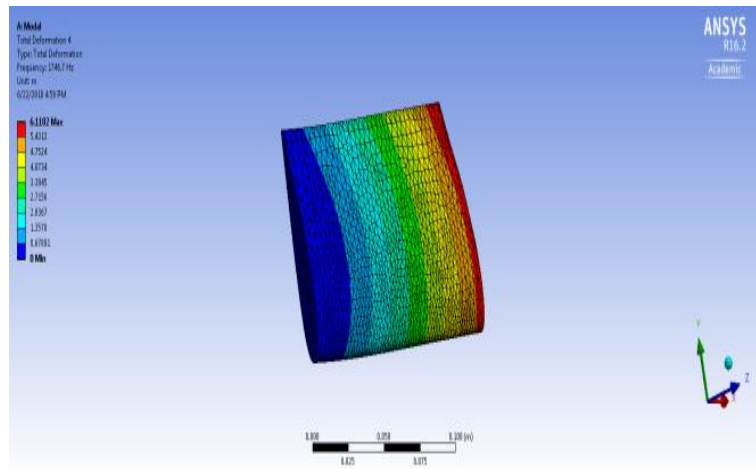

Fig. 58. $\quad 1746.7 \mathrm{~Hz}$ - Mode 4

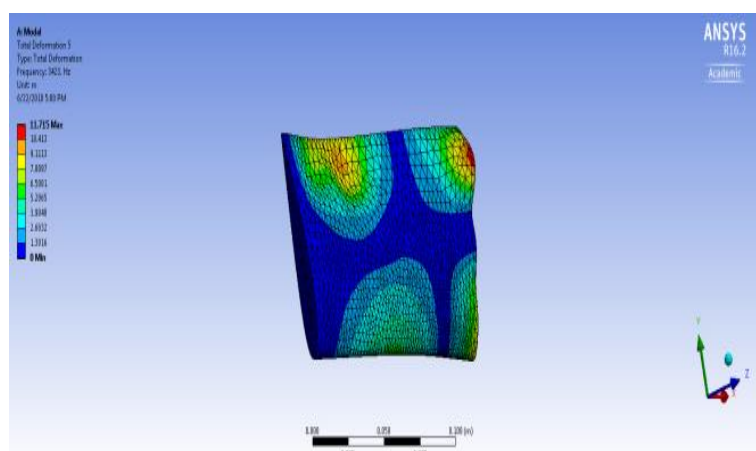

Fig. 59.

3423.0 Hz - Mode 5

Figures 55 to 59 shows the mode shapes of UAV wing for the given boundary conditions.

\subsubsection{Wind Turbine Blade - FSI Result}

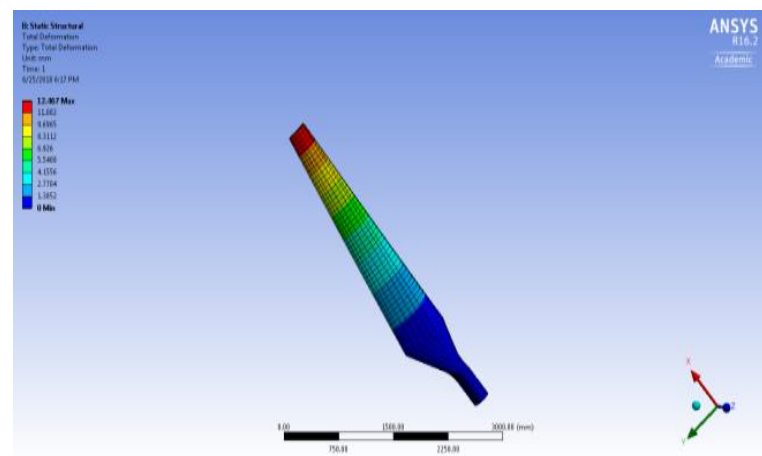

Fig. 60. Total Deformation

Published By: Blue Eyes Intelligence Engineering \& Sciences Publication 


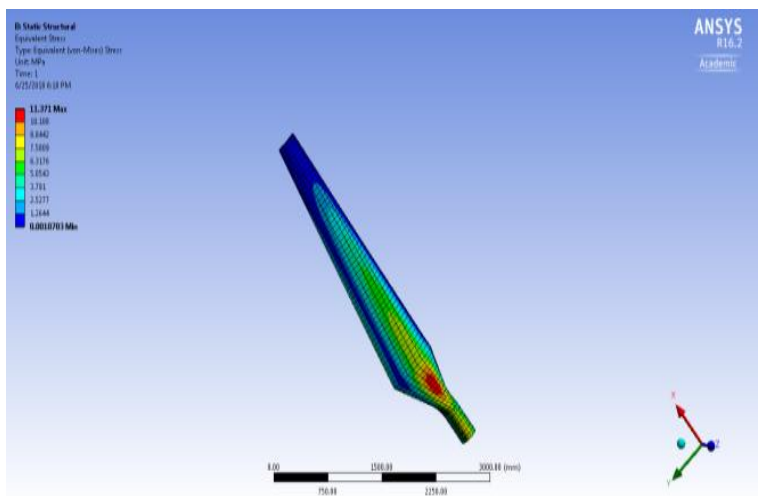

Fig. 61. Stress variations on wind turbine

Figure 60 and 61 shows the FSI simulations results of wind turbine blade.

\subsubsection{Wind Turbine Blade - Modal Analysis}

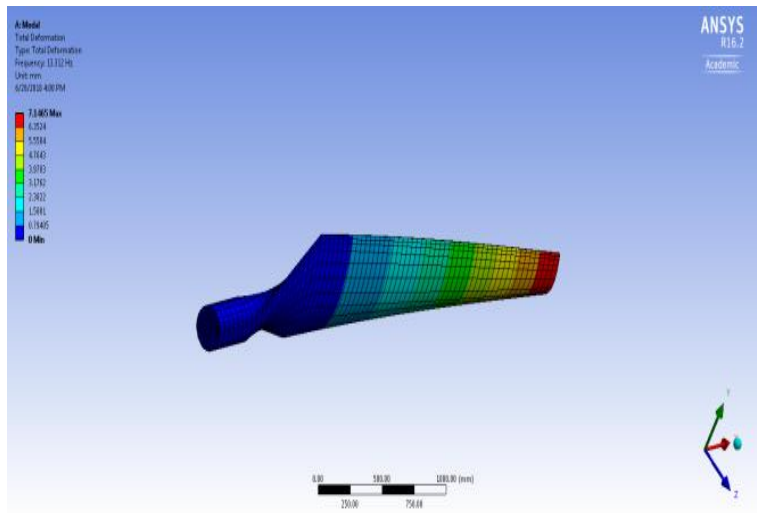

Fig. 62. $\quad 13.312 \mathrm{~Hz}-$ Mode 1

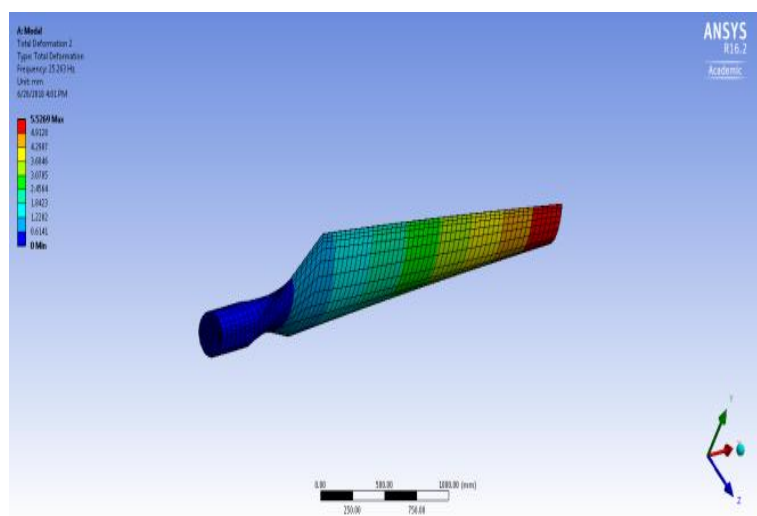

Fig. 63. $\quad 25.263 \mathrm{~Hz}-$ Mode -2

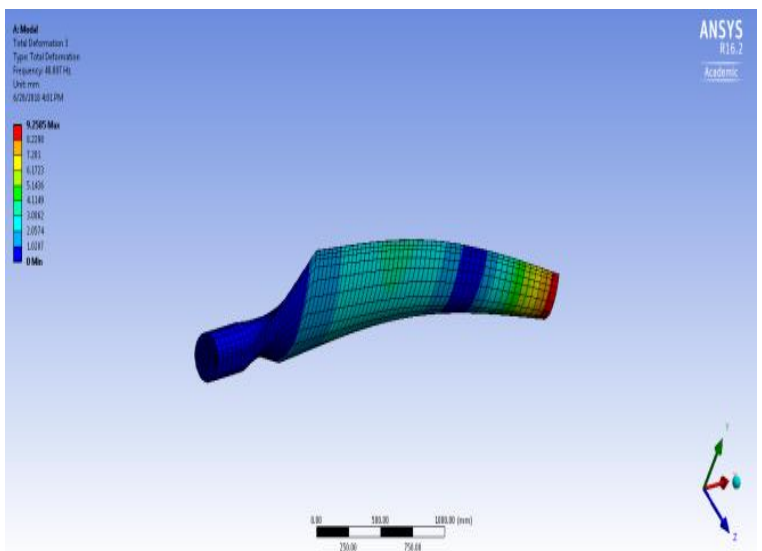

Fig. 64. $\quad 48.007 \mathrm{~Hz}-$ Mode -3

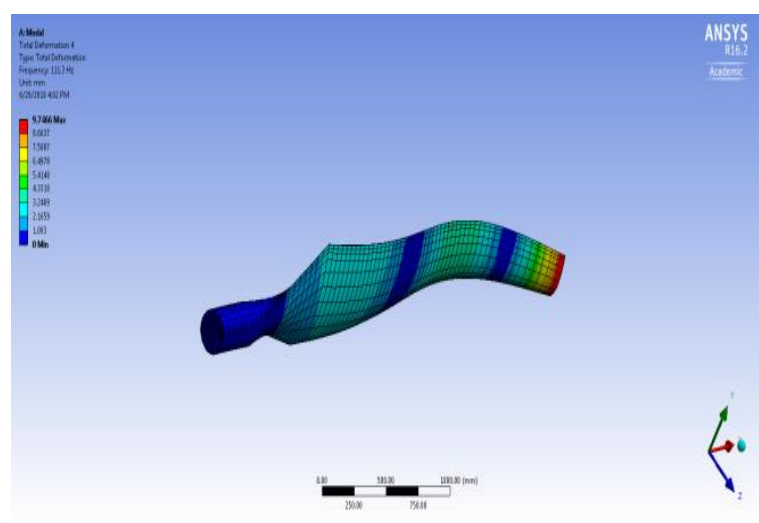

Fig. 65. $\quad 111.3 \mathrm{~Hz}-$ Mode -4

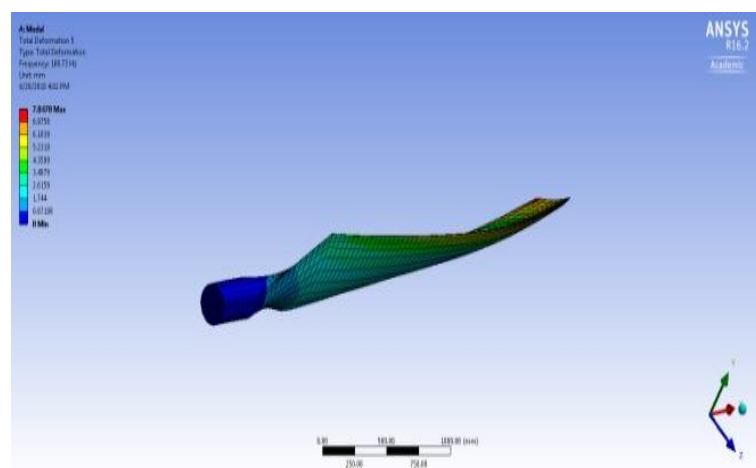

Fig. 66. $\quad 168.73 \mathrm{~Hz}-$ Mode -5

Natural frequencies of finalized have been predicted and revealed from figures 62 to 66

\section{CONCLUSION}

Composite material implementation in the cantilever structure based application is latest one, in which study about lifetime of various composite materials is mandatory one. The reference components of this article such as aircraft wing, UAV wing and wind turbine blade are modeled in CATIA V5. Two-Way coupling FSI analyses are executed with the help of Ansys Fluent 16.2 and Ansys Transient tool. Various mode shapes of various composite materials for different reference components are completed with the help of Ansys Workbench 16.2. From the stress, strain and deformation results understood that the values are within limit in the Kevlar and GFRP, hence these two materials are more suitable for cantilever structures.

\section{REFERENCES}

1. Vijayanandh $\mathrm{R}$ et al., Conceptual design and structural analysis of integrated composite Micro Aerial Vehicle, Journal of Advanced Research in Dynamical and Control Systems, Vol. 9. Sp- 14 / 2017, pp 857 - 881 .

2. Ahmad Reza Ghasemi and Masood Mohandes, Composite Blades of Wind Turbine: Design, Stress Analysis, Aeroelasticity, and Fatigue, Wind Turbines Design, Control and Applications, Intech open publisher, http://dx.doi.org/10.5772/63446, pp. $1-25$.

3. Vijayanandh R. et al., Vibrational fatigue analysis of NACA 63215 small horizontal axis wind turbine blade, Materials Today: Proceedings, Volume 5, Issue 2, Part 2,

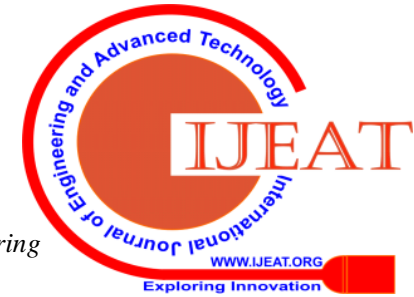


2018, Pages 6665-6674, https://doi.org/10.1016/j.matpr.2017.11.323

4. Sowdager Moin Ahmed, Design and Analysis Of Horizontal Axis Windmill Turbine Blade, International Journal Of Innovative Research \& Development, ISSN $2278-0211,2015$, Vol 4 Issue 2, pp $275-302$.

5. T Westphal and R P L Nijssen, Fatigue life prediction of rotor blade composites: Validation of constant amplitude formulations with variable amplitude experiments, Journal of Physics: IOP Conference Series, 2014, doi:10.1088/1742-6596/555/1/012107, pp $1-11$.

6. Mahmood M. Shokrieh and Roham Rafiee, Simulation of fatigue failure in a full composite wind turbine blade, Composite Structures 74 (2006), ISSN: 0263-8223, pp 332-342.

7. Konstantinos C. Bacharoudis, Stochastic analysis of structures made of composite materials, $\mathrm{PhD}$ thesis, defended in public on July 15th 2014 at University of Patras, pp 1 - 189.

8. Sethuramalingam, T. K., and B. Nagaraj. "A comparative approach on PID controller tuning using soft computing techniques." International Journal of Innovations in Scientific and Engineering Research (IJISER) 1, no. 12 (2014): 460-465.

9. Vijayanandh R. et al., Design Optimization of Advanced Multi-rotor Unmanned Aircraft System Using FSI, Book Title " Innovative Design, Analysis and Development Practices in Aerospace and Automotive Engineering (IDAD 2018)", Springer Series Title - Lecture Notes in Mechanical Engineering, eBook ISBN - 978-981-132718-6, Chapter number 28, DOI 10.1007/978-981-132718-6.

10. Neelabh Gupta, Structural Study and Parametric Analysis on Fatigue Damage of a Composite Rotor Blade, Master of Science Thesis for the MS in Sustainable Process and Energy Technology at Faculty of Mechanical, Maritime and Materials Engineering, Delft University of Technology, pp $1-85$.

11. David A Hensher, Fiber-Reinforced-Plastic Reinforcement for Concrete Structures: Properties and Applications, Elsevier publication, 2016, ISBN 148329143X, 9781483291437.

12. Vijayanandh R. et al., Material Optimization of High Speed Micro Aerial Vehicle using FSI Simulation, Procedia Computer Science, Volume Number 133, 2018, pp 2-9.

13. M Senthil Kumar, S Vijayarangan, Static analysis and fatigue life prediction of steel and composite leaf spring for light passenger vehicle, Journal of scientific and industrial research, Vol 66, February 2006, page no 128 134. 